\title{
Perwujudan Wawasan Nusantara dalam Kehidupan Berbangsa dan Bernegara
}

\author{
Cindy Qaula Agustin \\ IIK Surya Mitra Husada Indonesia
}

2121B0039

qaulacindy@gmail.com

\begin{abstract}
Abstrak
Wawasan Nusantara adalah cara pandang sebuah bangsa tentang dirinya ditengahtengah lingkungan strategis yang bergerak serba cepat dan dinamik, agar bangsa tersebut tetap eksis dan survife. Wawasan nusantara diharapkan mampu menyatukan pandangan-pandangan yang berbeda dalam masyarakat dan memberikan solusi untuk mendasari Ketahanan Nasional, sehingga tujuan nasional dapat terialisir. Perwujudan wawasan nusantara dalam kehidupan berbangsa dan bernegara merupakan salah satu proses pendewasaan pendirian manusia secara sistematis, dalam menjalani kehidupan secara bertanggung jawab dan berani mengambil keputusan serta tindakan yang bijaksana sekaligus berani menanggung berbagai konsekuensi yang ditimbulkan dalam kehidupan bermasyarakat.
\end{abstract}

\section{Latar Belakang}

Wawasan nusantara dalam kehidupan berbangsa dan bernegara yang mencakup kehidupan politik, ekonomi, sosial budaya, dan pertahanan keamanan harus tercemin dalam pola pikir, pola sikap, dan pola tindak yang senantiasa mengutamakan kepentingan bangsa dan negara kesatuan Republik Indonesia diatas kepentingan pribadi dan golongan. Dengan demikian, wawasan nusantara menjadi nilai yang menjiwai segenap peraturan perundang-undangan yang berlaku di seluruh wilayah negara, sehingga menggambarkan sikap dan perilaku, paham serta semangat kebangsaan atau nasionalisme tinggi yang merupakan identitas atau jati diri bangsa Indonesia. Dalam mewujudkan tujuan nasional banyak mengalami kendala, baik dalam tataran konsep maupun implementasinya. Setiap bangsa memiliki wawasan tersendiri, begitupun dengan masing-masing negara. Dalam 
penyelenggaraan kehidupaanya tidak terlepas dari pengaruh lingkungan dimana negara itu berada. Pengaruh yang ditimbulkan ini didasarkan pada hubungan timbal balik dalam semua segi atau aspek didalam suatu negara.

Untuk mengejar kejayaannya setiap bangsa juga harus memperhatikan faktorfaktor penting yaitu Bumi, Jiwa dan Lingkungan sekitar. Dimana bumi sebagai tempat atau ruang suatu bangsa bisa menempati untuk bertahan hidup, Jiwa dalam artian sebagai tekat dan semangat dari setiap individu untuk mencapai kejayaan atau cita-cita bangsanya. Wawasan nusantara diharapkan mampu menyatukan pandangan-pandangan yang berbeda dalam masyarakat dan memberikan solusi untuk mendasari Ketahanan Nasional suatu bangsa, sehingga tujuan nasional dapat terialisir. Wawasan Nusantara memberikan solusi untuk menyamakan pandangan yang sama sehingga dapat mewujudkan Integrasi nasional seperti yang diharapkan bangsa Indosnesia dan integrasi nasional dapat mewujudkan kesejahteraan, wawasan nusantara juga menjadi pola yang mendasari cara berpikir, bersikap, dan bertindak dalam rangka menghadapi berbagai masalah menyangkut kehidupan bermasyarakat,berbangsa dan bernegara. Implementasi wawasan nusantara senantiasa berorientasi pada kepentingan rakyat dan wilayah tanah air secara utuh dan menyeluruh. Perwujudan wawasan nusantara dalam kehidupan berbangsa dan bernegara merupakan salah satu proses pendewasaan pendirian manusia secara sistematis, dalam menjalani kehidupan secara bertanggung jawab dan berani mengambil keputusan serta tindakan yang bijaksana sekaligus berani menanggung berbagai konsekuensi yang ditimbulkan dalam kehidupan bermasyarakat.

\section{Kasus / Masalah}

- Mengapa wawasan nusantara penting dalam kehidupan?

- Bagaimana peran wawasan nusantara dalam berbangsa dan bernegara?

- Mengapa wawasan nusantara menjadi nilai yang menjiwai segenap peraturan yang ada?

\section{Tinjauan Pustaka}

Pengertian

Wawasan Nusantara adalah cara pandang sebuah bangsa tentang dirinya ditengah-tengah lingkungan strategis yang bergerak serba cepat dan dinamik, agar 
bangsa tersebut tetap eksis dan survife. Pengertian lain dari wawasan nusantara secara termininologi wawasan nusantara diartikan sebagai cara pandang sebuah nation state tentang diri dan lingkungan strategiknya yang berubah serba dinamik dengan mempertimbangkan aspek cultural, histories, geografis, ruang hidup, idealisme, falsafah Negara, konstitusi, aspirasi, identitas, integritas kelangsungan hidup dan perkembangan kehidupannya serta kemampuannya dan daya saingnya.Menurut M.Panggabean (1979 : 349) wawasan nusantara adalah doktrin politik bangsa Indonesia untuk mempertahankan kelangsungan hidup Negara Republik Indonesia, yang didasarkan pada Pancasila dan UUD 1945 dengan memperhitungkan pengaruh geografi, ekonomi, demografi, teknologi dan kemungkinan strategik yang tersedia. Dengan perkataan lain, wawasan Nusantara adalah geopolitik Indonesia. Dan nilai yang terkandung didalam wawasan nusantara telah diintegrasikan didalam lima aspek secara intern yaitu kesatuan wilayah, kesatuan bangsa, kesatuan ekonomi, kesatuan budaya, dan kesatuan pertahanan sedangkan untuk ekstern nilai integrasi itu diusahakan dengan ikut mewujudkan ketertiban dunia yang berdasarkan kemerdekaan perdamaian abadi dan keadilan sosial. Memperhatikan proses pertumbuhan itu, nyata benar bahwa wawasan nusantara tersebut masih terikat kepada konsepsi-konsepsi kekuatan. Oleh sebab itu, pemikiran-pmikiran yang kini sedang berkembang jelas mengarah kepada usaha untuk dapat menyusun dan merumuskan" Wawasan Nusantara" sebagai suatu "Wawasan Nasional", yang tidak hanya diperuntukkan bagi Hankamnas saja, melainkan yang dapat menyeluruh meliputi "segenap segi kehidupan nasional", hingga dapat mendasari konsepsi ketahanan nasional. Demikianlah tumbuh pemikiran-pemikiran dan pengkajian mengenai wawasan nusantara sebagai salah satu aspek daripada falsafah hidup nasional kita, yang berisi dorongan-dorongan dan rangsangan-rangsangan untuk mencapai tujuan serta aspirasi-aspirasi nasional kita. Wawasan nusantara adalah Geopolitik Indonesia, berwawasan dua arah yaitu keluar dan kedalam. Pancasila dan pembukaan UUD 1945 menetapkan nilai instrinstik yang mendasari wawasan nusantara yang nilai integrasi yang di tujukan pada kehidupan internal bangsa maupun kehidupan antar bangsa.

\section{Fungsi Wawasan Nusantara}

Wawasan Nusantara berfungsi sebagai pedoman, motivasi, dorongan, sertarambu-rambu dalam menentukan kebijaksanaan, keputusan, tindakan dan 
perbuatan bagi penyelenggara negara di tingkat pusat dan daerah maupun bagi seluruh rakyat Indonesia dalam kehidupan bermasyarakat, berbangsa, dan bernegara.

Unsur dasar Wawasan Nusantara

1. Wadah (countour)

2. Isi (content)

3. Tata Leku (conduct)

Asas Wawasan Nusantara

1. Solidaritas

2. Kejujuran

3. Kesamaan Tujuan

4. Keadilan

5. Kerja Sama

\section{Pembahasan}

Dalam perkembangan dunia sekarang ini banyak dijumpai berbagai macam sikap dan tingkah laku yang kurang bahkan sangat merugikan masyarakat, hal ini juga dipengaruhi dengan kurangnya pengetahuan atau wawasan tentang bagaimana hidup berbangsa dan bernegara yang baik, sebagaimana tercantum dalam butirbutir Pancasila dan UUD 1945. Berdasarkan falsafah pancasila bahwa manusia Indonesia adalah makhluk ciptaan Tuhan Yang Maha Esa, memiliki naluri, ahklak, daya pikir dan sadar akan keberadaanya yang saling terhubung baik itu dengan sesama, lingkungan, alam dan penciptanya untuk mempertahankan eksistensi dan kelangsungan hidup. Sebagai manusia yang mengerti akan wawasan nusantara juga diajarkan bagaimana cara agar dapat menerapkannya dalam masyarakat, tetapi yang terjadi justru sebaliknya, yang sebenarnya sudah mengetahui hal tersebut justru menjadi pemicu terjadinya hal tersebut. Sehingga apa yang dipelajari menjadi sia-sia. Oleh karena itu wawasan nasional Indonesia tidak disalah artikan oleh masing-masing individu, tetapi dimengerti dan dijalankan demi terciptanya persatuan dan kesatuan dengan tidak menghilangkan ciri, sifat dan karakter kebhinekaan sebagai unsur pembentuk bangsa yakni suku-suku bangsa, etnis, golongan dan daerah itu sendiri. 


\section{Kesimpulan}

- Dari pembahasan di atas dapat disimpulkan bahwa wawasan nusantara adalah cara pandang dan sikap bangsa Indonesia mengenai diri dan bentuk geografinya berdasarkan Pancasila dan Undang-Undang Dasar Negara Republik Indonesia Tahun 1945 (UUD 1945).

- Wawasan nusantara dalam kehidupan berbangsa dan bernegara mencakup berbagai aspek yaitu falsafah pancasila, pembangunan nasional, satu kesatuan politik, satu kesatuan ekonomi, satu kesatuan sosial dan budaya, serta satu kesatuan pertahanan keamanan dan luas wilayah Indonesia

\section{Daftar Pustaka}

Agustin, C. Q. (2021). Penerapan Demokrasi dalam Pelayanan Kesehatan.

Agustin, C. Q. (2021). Hak dan Kewajiban Pemerintah dan Warga Negara Saat Pandemi Covid-19.

Agustin, C. Q. (2021). Pancasila Sebagai Solusi dari Keanekaragaman dan Perbedaan.

Oktoriani, E. N., Sutrisno, J., Mayasari, E., \& Sodik, M. A. (2018). Analysis of medical record complete flexibility to complete claims of health BPJS RS Baptis Kota Batu. Journal of Global Research in Public Health, 3(1), 46-53.

Sodik, M. A. (2018). Merokok \& Bahayanya.

Attoriq, S., \& Sodik, M. A. (2018). Pencegahan Dan Pengendalian Infeksi Terkait Pelayanan Kesehatan Di Lahan Praktik.

Siyoto, S., Dwianggimawati, M. S., Sari, D. K., Mufida, R. T., \& Sodik, M. A. (2018). The Effect of Pornography Accessity to Influence Sexual Behavior. Indian Journal of Public Health Research \& Development, 9(12).

Al Annas, S. N. N., Indasah, I., Yudhana, A., \& Sodik, M. A. (2018). Analysis of Using Basic Material and Process on Organoleptic Result of Tempe Chips in Ngantru Trenggalek. Indonesian Journal of Nutritional Epidemiology and Reproductive, 1(1), 46-55. 